\title{
Retrospective Study of Snakebites in Nawalpur Snakebite Treatment Center, South-central Nepal
}

\author{
Shrestha BR ${ }^{1}$, Thapa-Magar C ${ }^{2}$ and Pandey DP3,4* \\ 1National Academy of Medical Sciences, Bir Hospital, Nepal \\ ${ }^{2}$ Kaligandaki Foundation, Kaligandaki Hospital, Nepal \\ ${ }^{3}$ South Asian Clinical Toxicology Research Collaboration, Faculty of Medicine, University \\ of Peradeniya, Sri Lanka
}

${ }^{4}$ School of Medicine and Public Health, Faculty of Health and Medicine, University of Newcastle, Newcastle, Australia

*Corresponding author: Pandey DP, Department of Veterinary Microbiology and Parasitology, Agriculture and Forest University, Rampur, Chitwan, Nepal, Tel: (977) 9845055137; Email: debpandey@gmail.com

\section{Abstract}

Snakebite is a pronounced health problem in the rural tropics and the subtropics of Nepal. However, only fragmentary hospital-based epidemiological data are available. We aimed to determine the incidence of snakebites and describe demographic characteristics, circumstances, seasonal patterns, and outcomes of snakebite treatment in the south-central region of Nepal. We retrospectively studied snakebite records maintained for the seven-month interval between July 2013 and January 2014 in the Nawalpur Snakebite Treatment Center, Netragunj, Sarlahi District. Records were reviewed and data collected during the interval from 01 February through 31 July 2017. Data were analyzed using descriptive statistics. A total of 396 snakebite case records were identified during the seven-month interval. 386 (97\%) were nonenvenomed cases, and $10(3 \%)$ were envenomed cases, which included three deaths (30\% case fatality rate). We estimated annual incidence of 26 snakebites, 1 envenomation, and 0.2 death per 100,000 people. An average of 16 vials (range = 6-29) of Indian polyvalent antivenom (VINS Bioproducts Limited, India) were administered in envenomed cases. None of the patients performed the WHO recommended first aid measures. Patients were transported to the center via motorcycle $(n=319,81 \%)$ most often. Snakebite is a significant problem for farmers suggesting it to be an important occupational health hazard in Sarlahi District and vicinity. No use of WHO recommended first aid measures suggests a limited scope of snakebite education in this region. Further, a prospective study of snakebites is needed to understand pre-hospital care practices, and circumstances and details of confirmed snakebite cases.

Keywords: Epidemiology; Envenomation; Case Fatality Rate; Circumstances of Snakebite; Prehospital Intervention

\section{Introduction}

Snakebite affects mainly rural areas of tropical and subtropical countries, particularly South Asian countries where medical management of snakebite is inefficient [1]. Snakebite is a serious problem in rural Nepal particularly in its southern lowlands. In Nepal, the snakebite case fatality rates ranged $3 \%$ to $58 \%$ [2]. A study carried out in 
five villages within the snakebite prone south-eastern region of Nepal reported an annual incidence of 1,162 envenomed cases per 100,000, and 162 deaths per 100,000 populations [3]. Poor public awareness about pre-hospital care of snakebite, the seeking traditional healers for the snakebite care, and no, or limited, facilities with snakebite treatment capabilities that are within an accessible distance from the locality of snakebite occurrence are major challenges to snakebite management in Nepal [4,5]. Although the World Health Organization re-considered snakebite as a neglected tropical disease, it is not yet included in the national health research priorities in Nepal $[6,7]$.

Furthermore, accurate and comprehensive epidemiological data concerning snakebite is still lacking in Nepal. Existing hospital data are limited and poor and underestimate the incidence of snakebites [1]. The available fragmentary epidemiological data cannot accurately represent the national snakebite problems because rainfall patterns vary between eastern and western Nepal [8]. Variations in rainfall patterns eventually regulate the distribution and diversity of snakes. Additionally, there exists pronounced sociocultural and physiographic diversity. These have been obstacles for the implementation of strategies for snakebite prevention, and pre- and in-hospital management of snakebites. The Nepal government provides snakebite treatment with freely supplied antivenom.

Although the Nepal Government reports 26 districts to be at high risk of snakebite envenomation and deaths, this risk does occur in other districts, too $[9,10]$. In Sarlahi, snake distribution has been determined $[11,12]$ without documenting snakebite problems. Herein, we sought to characterize snakebite cases admitted in Nawalpur Snakebite Treatment Center that received cases from six districts (Figure 1) and determine the burden of snakebite, the proportion of envenomation cases compared to non-envenomation cases, and case fatality rates. Understanding the snakebite epidemiology in south-central lowlands of Nepal based at this center may be helpful to improve pre- and in-hospital management of snakebite patients in Nepal. This study's results imply that snakebite is a significant problem in this region, primarily affecting those involved in agriculture and associated activities. From among the collections maintained in this center during the $\mathrm{PhD}$ research program, DPP identified two front-fanged venomous snake species (Bungarus caeruleus, Naja naja), one rearfanged mildly venomous snake species (Boiga trigonata), and one nonvenomous snake species (Lycodon aulicus) that were involved in snakebite [13].

\section{Methods}

\section{Study Site}

Nawalpur Snakebite Treatment Center, located in south-central Nepal, received cases of snakebite from a total population of 1,508,734 that are inhabitants of the Sarlahi and Mahottari Districts, and certain villages in Rautahat, Bara, Makawanpur, and Sindhuli Districts (Figures 1-3). We used this reference population to calculate the incidence of snakebite, envenomation, and death. Out of 83 snakebite treatment centers nationwide (pers. comm., Abinash Singh, Epidemiology and Disease Control Division, Nepal Government), the Nawalpur Snakebite Treatment Center was one of the healthcare institutions that maintained systematic medical records of snakebite.

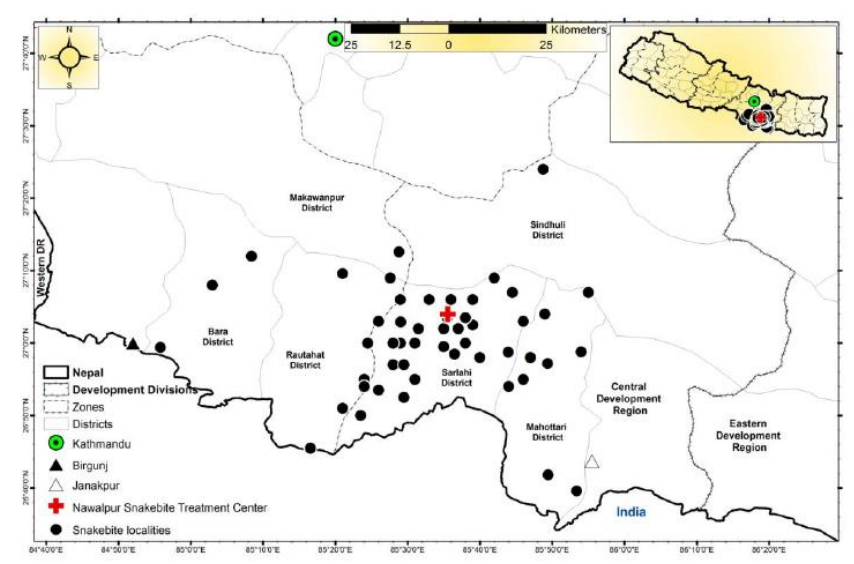

Figure 1: Map showing localities of villages and towns from where snakebite cases were reported to the Nawalpur Snakebite Treatment Center, Netragunj, Sarlahi District. 


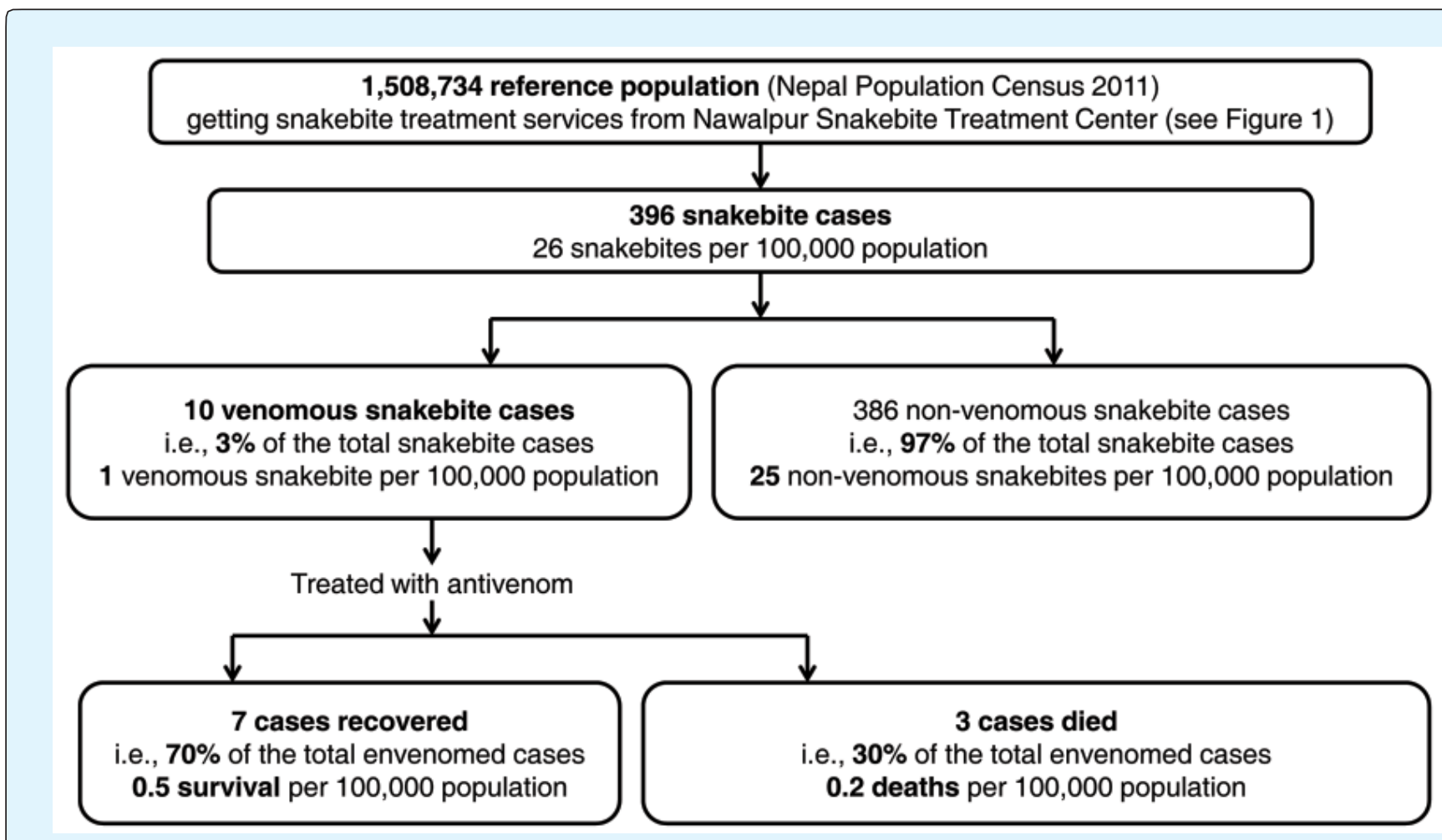

Figure 2: Flow diagram showing vulnerable populations to snakebite and snakebite cases reported to Nawalpur Snakebite Treatment Center, Netragunj, Sarlahi District.

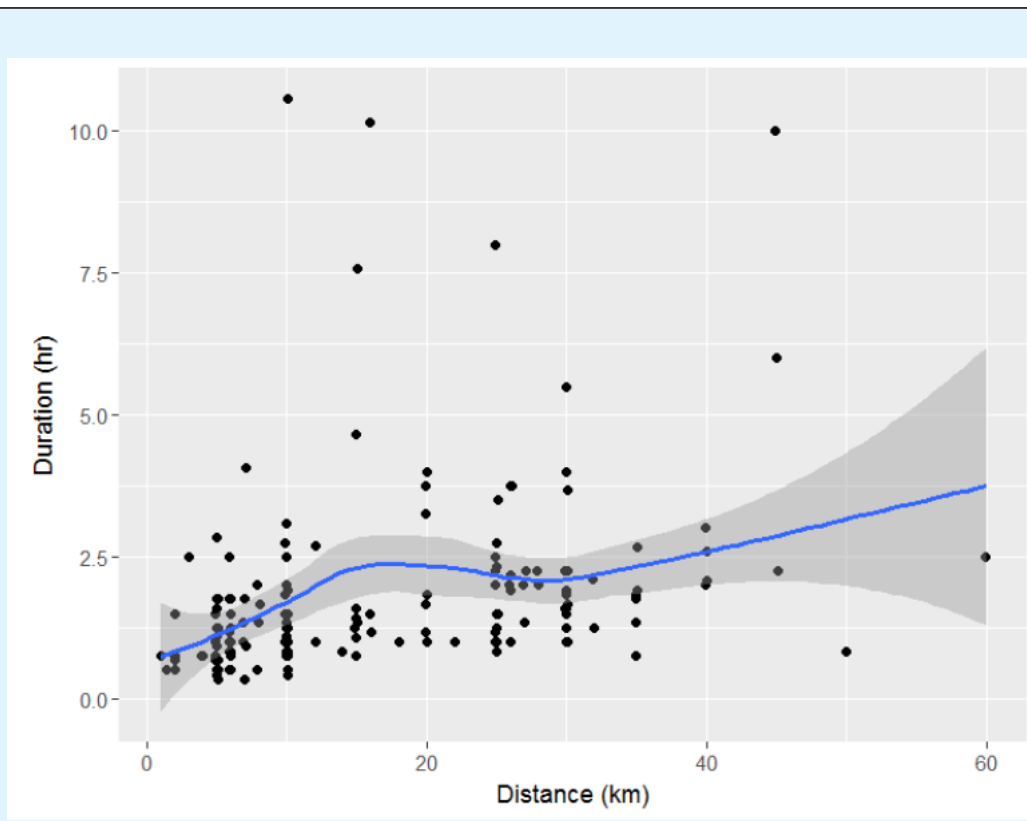

Figure 3: Dot plot showing distance between locality of the snakebite occurrence and the Nawalpur Snakebite Treatment Center (NSTC), and time lapse between snakebite and access to NSTC. Smooth regression line with a shaded gray area represents point-wise 95 percent confidence regions for the true mean of duration as a function of distance. 
Almost all snakebites occurred in agrarian terrain, less than $300 \mathrm{~m}$ above sea level (asl), having tropical climate with the annual rainfall of $1834 \mathrm{~mm}$, and minimum and maximum temperature of 16 and 40 degree Celsius $\left({ }^{\circ} \mathrm{C}\right)$, respectively. A few villages particularly from Makawanpur and Sindhuli Districts were located in the southern foothills of great Himalaya between 300-1,000 $\mathrm{m}$ asl (Figure 1), having subtropical climate with the annual rainfall of $1822 \mathrm{~mm}$, and minimum and maximum temperature of 16.7 and $29.2^{\circ} \mathrm{C}$, respectively. The rainfall season occurs from June to September (peak of rainfall occurs in July/August). In November to March, there is the lowest rainfall. Forested areas in this region are dominated by Sal (Shorea robusta) and fertile agricultural landscapes by paddy, maize, and wheat, etc. The major rivers running across one of these six districts were Kamala, Bagmati, Lakhadei, Jhim, etc. These river systems including tropical and sub-tropical climate, high temperatures, rainfall, and fertile agrarian lands indicate that these districts are prone to the occurrence of snakebite.

\section{Data Collection}

We retrospectively studied snakebite records maintained from July 2013 to January 2014 in the Nawalpur Snakebite Treatment Center, Netragunj, Sarlahi District, south-central Nepal (Figure 1). Ethical Review Board of Nepal Health Research Council approved this study. We collected snakebite patients' demographic characteristics (i.e., age, gender, occupation, religion, nationality), circumstances of snakebite (i.e., time, month, and seasons, offending snake seen, site of bites), activities of patient while snakebite occurred, pre-hospital intervention (first aid, visiting traditional healers or other healthcare centers), duration (in hours) between time of snakebite and access to the center, the estimated distance $(\mathrm{km})$ from snakebite locality (based on permanent address mentioned in the record file and Google Earth Map) to the center, use of transport, past history of snakebite, duration of hospital stay (days), total envenomed cases and vials of antivenom used, and outcomes during the interval from 01 February through 31 July 2017.

Medical records included cases of confirmed snakebites based on an eyewitness and/or claim of victim, snakes involved were brought in (species were not mentioned in medical records), clear signs of snakebite wounds, and symptoms of snakebite envenomation. Those cases with inaccurate claim of snakebite and with poor or no evidence of snakebite were excluded. We defined absence of values for the mentioned variables in medical record as "Not Available" or "NA". For the age group below six years, we considered occupation as "NA" because their formal education begins at six years age.

\section{Data Analysis}

Our study included data from the peak snakebite months (July, August, and September). In other months snakebites are rare or do not occur. We excluded snakebite cases from India when analyzing annual incidence. We determined a total population by adding the populations of Sarlahi and Mahotari Districts, and the villages and municipalities for other districts (Population Census 2011) from where snakebite cases were admitted to the Nawalpur Snakebite Treatment Center. Therefore, our analyses of annual incidence of snakebites, envenomations, and deaths indicate a reasonable estimate of the annual incidence (Figure 2). In some parts of India, the snakebite patterns were based on cultural practices and religion [14]. Therefore, we calculated and analyzed distribution of snakebite based on religion. We analyzed data by means of descriptive statistics, Wilcoxon signed rank test (for non-normally distributed data), and Chi-square goodness of fit test (for categorical variables) using R statistical programming (R version 3.2 .5 (201604-14)). We determined the normality of data using a histogram and Shapiro-Wilks test, and the outliers using box plots and Grubbs test. All tests were performed at a $5 \%$ significance level.

\section{Results}

\section{Incidence of Snakebite, Envenomation, and Deaths}

A total of 396 patients with history of snakebites from six districts (Figure 1) presented to the Nawalpur Snakebite Treatment Center, Netragunj during the sevenmonth period resulting in an annual incidence of 26 snakebites per 100,000 people. Ten of 396 patients (3\%) developed signs of envenomation resulting in an annual incidence of one envenomation per 100,000 people. Three of the 10 envenomed patients admitted in the center had a fatal outcome resulting in $30 \%$ case fatality rate and an annual incidence of " 0.2 " snakebite death per 100,000 people (Figure 2).

All cases of envenomation developed neurotoxicity (blurred vision, ptosis, and difficulties in swallowing and respiration) and required antivenom treatment. None of the cases reported evidence of haemotoxic envenomation. The average amount of Indian polyvalent antivenom (VINS Bioproducts Limited, India) administered to all envenomed snakebite patients was $16 \pm 3$ vials $(n=9$, one medical record did not document the amount of antivenom used; range $=6-29$, median $=15, \mathrm{sd}=8.23$, 
$95 \%$ confidence interval $=9-26)$. An average of $14 \pm 2$ vials were administered to the seven survived patients only (range $=9-23$, median $=13.5, \mathrm{sd}=5.16,90 \%$ confidence interval $=10-19$ ).

\section{Demographic Characteristics}

The majority of snakebites were confined to adults aged 18-40 years $(\mathrm{n}=196,50 \%, \mathrm{p}=0.056)$ (Table 1$)$.
Females were marginally dominant with respect to the total number of snakebite victims $(51 \%, \mathrm{n}=202)$. Farmers $(54 \%, \mathrm{n}=214)$, followed by students $(25 \%, \mathrm{n}=$ $100)$ and housewives $(10 \%, \mathrm{n}=41)$ suffered the majority of snakebites (Table 1). Snakebite cases from six districts in south-central Nepal were reported to the center (Figure 1).

\section{Features of snakebite cases}

Number (\%) [All snakebite cases [n =396)]

\section{A. Demographic factors}

1. Age (years) of all patients [range $=2-108$, median $=29$, $s d=17.15$, mean $\pm S E M=31.72 \pm 0.86$, Wilcoxon signed rank test value $=42540, \mathrm{p}=0.047 ; 95 \%$ confidence interval $=29-32.5, \mathrm{n}=395]$

$1-17$ (children) [range $=2-17$, median $=13, \mathrm{sd}=4.20$, mean $\pm \mathrm{SEM}=11.81 \pm$ 0.44 , Wilcoxon signed rank test value $=1475.5, \mathrm{p}=0.063$ ]

$18-40$ (adults) [range $=18-40$, median $=28, \mathrm{sd}=7.22$, mean $\pm \mathrm{SEM}=28.97 \pm$ 0.52 , Wilcoxon signed rank test value $=10102, \mathrm{p}=0.056]$ 41-65 and above aged (elders) [range $=41-108$, median $=52, \mathrm{sd}=10.66$, mean \pm SEM $=54.25 \pm 1.04$, Wilcoxon signed rank test value $=3030.5, \mathrm{p}=$ $0.123]$

2. Gender [sex (male and female) ratio $=0.96$, Chi-squared test value $=0.16162, \mathrm{df}=1, \mathrm{p}=0.687$ ] Male

Female

3. Occupation [Chi-squared test value $=1428.7, \mathrm{df}=11, \mathrm{p}=<0.001$ ]

Farmer

Student

Housewife

Businessman

Salaried job

Teacher

Skilled worker

Housemaid

Veterinary doctor

Police

Driver

Security guard

Not available (includes patient aged below 6 years, too)

4. Religion [Chi-squared test value $=662.57, \mathrm{df}=3, \mathrm{p}=<0.001]$

Hindu

Buddhist

Islam

Christian (= Isai)

Not available

\section{Distribution of snakebites}

Nepal: Districts

Sarlahi

Mahottari

Rautahat

Bara

Makwanpur

Sindhuli
$93(23)$

$196(50)$

106 (27)

194 (49)

202 (51)

$214(54)$

100 (25)

$41(10)$

$11(3)$

4 (1)

$3(0.8)$

$3(0.8)$

$2(0.5)$

$1(0.3)$

$1(0.3)$

$1(0.3)$

$1(0.3)$

$14(4)$

$316(80)$

67 (17)

$9(2)$

$3(0.8)$

$1(0.3)$ 


\begin{tabular}{|c|c|}
\hline India: Sitamarhi, Bihar & $1(0.3)$ \\
\hline Not available (incomplete address or address not mentioned) & $13(3)$ \\
\hline \multicolumn{2}{|l|}{ B. Circumstances of snakebites } \\
\hline \multicolumn{2}{|l|}{ 1. Time \# [Chi-squared test value $=70.883, \mathrm{df}=4, \mathrm{p}=<0.001]$} \\
\hline Evening (17:00-19:59) & $113(29)$ \\
\hline Day (10:00-16:59) & $100(25)$ \\
\hline Night (20:00-02:59) & $95(24)$ \\
\hline Morning (05:00-09:59) & $64(16)$ \\
\hline Early morning (03:00-04:59) & $20(5)$ \\
\hline Not available & $4(1)$ \\
\hline \multicolumn{2}{|l|}{ 2. Months [Chi-squared test value $=283.22, \mathrm{df}=6, \mathrm{p}=<0.001$ ] } \\
\hline August & $146(37)$ \\
\hline September & $98(25)$ \\
\hline October & $71(18)$ \\
\hline July & $37(9)$ \\
\hline November & $29(7)$ \\
\hline December & $8(2)$ \\
\hline January & $6(2)$ \\
\hline Not available & $1(0.3)$ \\
\hline \multicolumn{2}{|c|}{ 3. Bitten body parts [Chi-squared test value $=1183, \mathrm{df}=7, \mathrm{p}=<0.001]$} \\
\hline Leg & $239(60)$ \\
\hline Hand & $127(32)$ \\
\hline Back of trunk & $4(1)$ \\
\hline Face & $2(0.5)$ \\
\hline Shoulder & $1(0.3)$ \\
\hline Ear & $1(0.3)$ \\
\hline Lips & $1(0.3)$ \\
\hline Not available & $21(5)$ \\
\hline \multicolumn{2}{|c|}{ 4. Activities while receiving snakebite [Chi-squared test value $=985.06, \mathrm{df}=15, \mathrm{p}=<0.001]$} \\
\hline Agricultural activities & $145(37)$ \\
\hline Sleeping & $72(18)$ \\
\hline Walking on the road & $56(14)$ \\
\hline House activities & $51(13)$ \\
\hline Using toilet & $23(6)$ \\
\hline Playing on the ground & $21(5)$ \\
\hline Resting at home & $6(2)$ \\
\hline Hotel activities & $2(0.5)$ \\
\hline Swimming & $2(0.5)$ \\
\hline Bathing & $1(0.3)$ \\
\hline Cleaning & $1(0.3)$ \\
\hline Combing hair & $1(0.3)$ \\
\hline Walking to school & $1(0.3)$ \\
\hline Walking to toilet & $1(0.3)$ \\
\hline Washing clothes & $1(0.3)$ \\
\hline Pulling piled up straw & $1(0.3)$ \\
\hline Not available & $11(3)$ \\
\hline \multicolumn{2}{|l|}{ 5. Did patient see snake after snakebite? } \\
\hline Yes & $169(43)$ \\
\hline No & $208(53)$ \\
\hline Not available & $19(5)$ \\
\hline \multicolumn{2}{|l|}{ 6. Past history of snakebite } \\
\hline Yes & $31(8)$ \\
\hline
\end{tabular}




\begin{tabular}{|l|c|}
\hline No & $305(77)$ \\
\hline Not available & $60(15)$ \\
\hline C. Pre-hospital interventions adopted & $11(3)$ \\
\hline 1. Medical treatment sought in other healthcare center & $363(92)$ \\
\hline Yes & $22(5)$ \\
\hline No & \\
\hline Not available & $11(3)$ \\
\hline 2. Treatment seeking behaviour & $377(95)$ \\
\hline a. Consultation with Dhami/ Jhakri (local healers) & $8(2)$ \\
\hline Yes & \\
\hline No & $110(28)$ \\
\hline Not available & $278(70)$ \\
\hline a. First aid (tourniquets, incision, etc.) & $8(2)$ \\
\hline Yes & $319(81)$ \\
\hline No & $36(9)$ \\
\hline Not available & $14(4)$ \\
\hline 3. Modes of transport used & $7(2)$ \\
\hline Motorcycle & $5(1)$ \\
\hline Ambulance & $4(1)$ \\
\hline Van & $4(1)$ \\
\hline Bus & $3(1)$ \\
\hline Walking & $1(0.3)$ \\
\hline Bicycle & $3(1)$ \\
\hline Three-wheeler & \\
\hline Microbus & \\
\hline Police Van & \\
\hline Not available & \\
\hline $\begin{array}{l}\text { df = degree of freedom, sd = standard deviation, SEM standard error of mean }, \#=\text { unequal time frame signify the } \\
\text { period indicating risk time segment of the day }\end{array}$ & \\
\hline
\end{tabular}

Table 1: Demographic features, circumstances of snakebites, and pre-hospital intervention.

\section{Circumstances of Snakebites}

Snakebites mostly occurred in the evening ( $\mathrm{n}=113$, $29 \%)$, day $(n=100,25 \%)$, and night $(n=95,24 \%)$ (Table 1). The highest number of snakebite incidents occurred in August $(37 \%, \mathrm{n}=146)$ and September $(25 \%, \mathrm{n}=98 \%)$ (Table 1). The majority of snakebites occurred on lower limbs $(n=239,60 \%)$ followed by upper limbs $(n=127$, $32 \%)$, and then on the torso of the body $(\mathrm{n}=4,1 \%)$ (Table 1). Except for the permanent address of snakebite episode, the exact location of the occurrence of the snakebite such as indoor, outdoor, premises of the houses, agricultural fields, etc. were not documented in the medical records. 145 (37\%) patients were involved in agricultural activities at the time of snakebite, and 72 $(18 \%)$ were sleeping when the snakebite occurred (Table 1). $169(43 \%)$ patients saw the snake that was responsible for the bite and $31(8 \%)$ had been suffered from a snakebite at least once prior to admission to the center during the study period (Table 1 ).

\section{Pre-Hospital Interventions Adopted}

None of the patients performed any type of recommended first aid, i.e., pressure immobilization bandaging or local compression pad. 11 (3\%) patients sought support from a healthcare center and traditional healers, respectively, on the way to Nawalpur Snakebite Treatment Center. 319 (81\%) patients were transported to the center by motorcycle and $36(9 \%)$ by ambulance (Table 1).

\section{Duration and Distance}

The mean time duration between the snakebite and access to the Nawalpur Snakebite Treatment Center was $1.71 \pm 0.1$ hours $(\mathrm{n}=292$, range $=0.2-10.6$, median $=1.3$, $\mathrm{sd}=1.5,95 \%$ confidence interval $=1.4-1.6, \mathrm{p}=<0.001$ ). The mean estimated distance between the location where the snakebite occurred and the center was $17.1 \pm 0.9 \mathrm{~km}$ $(\mathrm{n}=174$, range $=1-60$, median $=13, \mathrm{sd}=11.9,95 \%$ confidence interval $=15-18, p=0.0002$ ) (Figure 3). The medical records did not include information about whether the snake involved was brought in dead or alive. 


\section{Discussion}

\section{Incidence of Snakebite, Envenomation, and Deaths}

The estimate of snakebite incidence in our study corresponds to the similar estimates from a study in Bharatpur Hospital, but it was much lower than that reported from a community-based survey carried in five villages in eastern lowlands of Nepal [2,3]. Our estimate of the incidence of snakebite fatalities (Figure 2) is comparable to that reported in similar study carried in the southeastern Nepal [15]. We recorded a 30\% case fatality rate (CFR) which is higher than previous reports from other parts of Nepal [21\%, 10 centers in eastern Nepal, 21\%, Bharatpur Hospital in south-central Nepal, $17 \%$ among 46 confirmed krait bite patients admitted in different hospitals of Nepal] $[2,13,16]$. But, it is considerably greater than the CFR $(13 \%)$ reported from 10 centers in western Nepal [1]. The CFR was comparable to findings in several previous studies carried in different parts of Nepal. Pandey reported 27\% CFR in a community-based study in central lowlands of Nepal [5]. CFRs can vary greatly; in Nepal ranging $3-58 \%$, and in Asia and Africa from $0.4-54 \%$ and $0.1-28 \%$, respectively $[2,17]$. The annual incidence of snakebites per 100,000 population reported in our study (Figure 2) corresponds to the estimate of annual incidence in a comprehensive study in Nepal [13]. The prevalence of snakebite death in Sarlahi District and vicinity is noticeably less than in India (i.e., six per 100,000 snakebite deaths) [18].

The misconception that "all snake bites cause envenomation" is deeply rooted among rural people in Nepal [4]. The proportion of envenomation cases (3\%) in our study is smaller than those reported in other similar studies in Nepal [5-19\%, southeastern regions, 12-42\%, south-central regions, 9-14\%, southwestern regions] $[1,5,15,16,19-22]$. Although our finding of a smaller proportion of snakebite envenomations is comparable to the report of 5\% envenomation from Choharwa snakebite treatment center [15], the reported variation in the rates of envenomation in previous studies reflects poor documentation of referred envenomed patients. Larger envenomation rates are reported from other South Asian countries [India, 34\%; Bangladesh, 35-40\%] [23-25].

The average amount of antivenom administered to envenomed snakebite patients in our study was lower than that reported in previous studies [2,20]. The Nepal Government provides antivenom to Nepalese citizens free of cost. Based on antivenom use patterns in the envenomed cases in our study, it is likely that there were no standard snakebite treatment guidelines followed. For the judicious use of antivenom a single, standardized protocol of snakebite treatment should be used.

\section{Demographic Characteristics}

The median age of snakebite patients in our series was 29 years (Table 1). This corresponds to the age reported in similar studies previously carried out in different parts of Nepal [(27-32 years, eastern Nepal , 36 years, central Nepal], and from other South Asian countries [31-38 years, India, 29-38 years, Bangladesh, 36 years, Sri Lanka, 33 years, Pakistan] [2,15,26-32]. Our finding that the highest number of snakebites occurred in adults aged 1840 years (Table 1) corresponds with several different hospital-based studies reported for Nepal [37\%, 21-40 years, eastern Nepal, 39-47\%, 20-40 years, central Nepal, $41 \%$, 21-40 years, western Nepal] and in other South Asian countries $[71 \%, 21-50$ years, India, 39\%, 20-34 years, Bangladesh, and 51\%, 21-40 years, Sri Lanka] [1, 16,20,33-35]. Snakebite problems confined to these highly productive age groups widely influence the socioeconomic aspects of peoples' lives. Therefore, a prospective study on socio-economic consequences owing to snakebite morbidity and mortality in the population of the productive age group should be carried out in Nepal.

Females dominated male snakebite victims by $2 \%$ in the present study. This is supported by the other similar studies reported for central and the western Nepal $[1,20]$. Unlike our findings, male preponderance is reported in other hospital-based studies [55\% males, south eastern Nepal, 54\% males, south-central Nepal, and 57-60\% males in an eco-epidemiological study of kraits and Russell's Viper bites in Nepal] [2,13,16]. Although we found snakebites more often confined to females than males, there were no significant differences in the number of snakebites according to gender $(p=0.687$, Table 1$)$. Female dominancy among snakebite victims in this region reflects a patriarch society where females are allocated to several households and field activities. Therefore, females are likely to encounter snakes more often than males. Further, the International Labor Organization mentioned the increasing trend of labor out-migration in Nepal (i.e., 500,000 labor migrants were registered for 2014 in Nepal Government offices). This trend might be a slight influence to the female preponderance of snakebites. However, we suggest performing a community-based survey of snakebite in order to know the influence of outmigration on the incidence of snakebites in the Nepalese community.

Our study clearly depicted that snakebite is a significant occupational health hazard $(\mathrm{p}=<0.001)$ in south-central Nepal (Table 1). Farmers were at the highest risk of snakebites in this region. Similar findings 
were reported in studies that involved other different area of Nepal, India, Bangladesh, and Sri Lanka $[1,2,28,36]$. Unlike in some parts of India, distribution of snakebites based on religion (Table 1) corresponds to the population of the particular religion practiced in Sarlahi District and vicinity [14].

\section{Circumstances of Snakebites}

Altogether, the darker hours of the day (evening and night) that occur during August and September while people are involved in agricultural activities and sleeping (Table 1) represented an increased risk for snakebite accidents in the lowlands of Nepal. The occurrence of snakebite in the present study at night, which was determined from all snakebite cases, was less than in the evening and day, but was greater than those reported in a prospective study in Bharatpur Hospital [2]. It may be because the study in Bharatpur Hospital interpreted only envenomed cases.

We found distinct seasonal patterns of snakebites that were closely related to rainfall and temperature, as reported in other parts of Nepal $[2,3,22]$. As reported in previous studies, the most of snakebites occurred in August in Sarlahi District and vicinity. However, understanding the degree of association of snakebite patterns with rainfall amounts, rainfall patterns, and temperatures is essential to implementation of snakebite prevention strategies.

The majority of snakebites were inflicted on the extremities of the body corresponded to their involvement in agricultural and associated activities. We found most of the bites occurred on the lower limbs $(60 \%)$, which is similar to the findings from similar studies in India (86\%) [28]. We suggest that to improve medical records should include precise localities such as indoor, premises of the house, roadsides, and other location descriptions of immediate surroundings of the locality where bite occurred. The locality and bite time information may help clinicians to surmise snake species involved, and help them be prepared for better management of snakebite patients, and to develop preventive measures against snakebites.

Approximately $40 \%$ of snakes involved in bites were visibly observed and correspond to snakebite episodes that occurred during daylight hours while individuals were engaged in household activities (Table 1). This provides for an opportunity to educate people on the identification of snakes involved [4]. The community education is essential for enabling people to adopt proper measures for pre-hospital care and for the prevention of snakebite. Non-visibility of snakes is likely a result of snakebite episodes having occurred during the dark hours of the day, while individuals were engaged in bushy agricultural land work, or sleeping (Table 1).

\section{Pre-Hospital Interventions Adopted}

No use of proper or improper first aid ( $n=110,28 \%$ ), and patient visits to traditional healers on the way to the snakebite treatment center compromised effective snakebite management resulting in poor outcomes. This limited use of WHO recommended first aid measures, and consulting with faith healers is also common in other parts of Nepal [13,37]. The use of motorcycles to transport the majority of patients (Table 1) relates to their ready availability and their affordability to the people. Driving a motorcycle on dirty roads, especially during rainy season, and at night increases the risk of road accidents. Therefore, a network of ambulance transportation should be developed so that people from distant rural areas could be transported to a snakebite treatment center in a timely and safely. This process would also provide support for other emergency healthcare needs.

\section{Duration and Distance}

Patient time procuring transport, applying first aid, and visiting traditional healers all contribute to a delay in the time to treatment. Snakebite patients were usually within one hours driving distance if roads were normal, and transport vehicles were immediately available. The lack of proper roads and rapid comfortable transportation remain major challenges in this region for emergency transport of snakebite victims to the center. Similar problems exist nationwide [2,5]. Snakebites often occur among people inhabiting agrarian and rural areas where transportation is inadequate or unavailable. Thus, victims are physically carried to the local healers, and are at risk of dying on the way to the healthcare center, resulting in deaths not being reported to healthcare facilities.

\section{Constraints of the Study}

- Patient presented in this treatment centre were not recorded with the specific snake taxa responsible for the envenomings. The "non-envenomed" patients might have been bitten by a venomous species [dry bite] or they were incorrectly identified and mentioned in the medical records.

- As we calculated the annual incidence of snakebites based on the 2011 population census data (Figure 1), our estimate of annual incidence may be a deviation from the actual incidence if they are considered for real time population context. 
- Some cases might be referred to higher treatment centers without medical records. Therefore, snakebite incidence should be higher than our reports.

\section{Conclusion}

Evaluating aforementioned snakebite incidence and potential limitations, we estimate that snakebite burden in the study area is greater than those reported in other similar studies in Nepal. Prospective studies and community surveys are needed to ascertain the precise burden of snakebite in this region. Snakebite medical records should be comprehensive (including locality details of snakebite, expert species identification if a dead snake is presented to healthcare system) with improved data record storage using modern technology and sufficient human resources.

The data keeping should be regularly monitored by higher authorities to ensure completeness of the records. These elements are essential for improving effective snakebite management in Nepal. The higher incidence of evening and nighttime snakebite may be reduced by the use of torch lights, wearing gum boots while performing activities in dark conditions, and using mosquito-net while sleeping.

\section{Competing Interests/ Disclosures}

None. The authors declare that they have no competing interests.

\section{Authors Contribution}

DPP conceived the study. DPP, BRS, and CT-M involved in acquisition of data, drafting manuscript. Data entry was done by BRS, data crosscheck and analysis by DPP and BRS. Critical revisions of manuscript were done by DPP. All authors read and approved the final version of the manuscript.

\section{Acknowledgement}

We are thankful to all staff personnel in the Nawalpur Snakebite Treatment Center for the access to copies of snakebite medical records maintained in this center. We are especially grateful to Dr. Keyler DE, Department of Experimental and Clinical Pharmacology, University of Minnesota, Minneapolis, MN, USA for his review of this article.

\section{Funding (Financial/Material Support)}

None. DPP's research on snakebite in Nepal was supported by the South Asian Clinical Toxicology Research Collaboration and NHMRC CRE APP1110343, Australia.

\section{References}

1. Magar CT, Devkota K, Gupta R, Shrestha RK, Sharma SK, et al. (2013) A hospital based epidemiological study of snakebite in Western Development Region, Nepal. Toxicon 69: 98-102.

2. Pandey DP, Vohra R, Stalcup P, Shrestha BR (2016) A season of snakebite envenomation: presentation patterns, timing of care, anti-venom use, and case fatality rates from a hospital of southcentral Nepal. J Venom Res 7: 1-9.

3. Sharma SK, Chappuis F, Jha N, Bovier PA, Loutan L, et al. (2004) Impact of snakebites and determinants of fatal outcomes in southeastern Nepal. Am J Trop Med Hyg 71(2): 234-238.

4. Pandey DP, Pandey SG, Devkota K, Goode M (2016) Public perceptions of snakes and snakebite management: implications for conservation and human health in southern Nepal. J Ethnobiol Ethnomed 12(1): 22.

5. Pandey DP (2007) Epidemiology of snakebites based on field survey in Chitwan and Nawalparasi Districts, Nepal. J Med Toxicol 3(4): 164-168.

6. Chippaux JP (2017) Snakebite envenomation turns again into a neglected tropical disease! J Venom Anim Toxins Incl Trop Dis 23(1): 38.

7. Nepal Health Research Council (2013) Nepal Health Research Council and national health research priorities in Nepal. Kathmandu: Nepal Health Research Council.

8. Practical Action Nepal (2009) Temporal and spatial variability of climate change over Nepal (1976-2005). Kathmandu: Practical Action Nepal pp: 76.

9. Bista MB, Banerjee MK, Thakur GD, Shrestha JM, Upadhyay PK, et al. (2005) Incidence of poisonous snakebite in Nepal. Kathmandu: Department of Health Services, Epidemiology and Disease Control Division, Ministry of Health, Government of Nepal. 


\section{Advances in Clinical Toxicology}

10. Pandey DP, Sharma SK, Alirol E, Chappuis F, Kuch U (2016) Fatal neurotoxic envenomation following the bite of a Greater Black Krait (Bungarus niger) in Nepal: a case report. J Venom Anim Toxins Incl Trop Dis 22: 19.

11. Pandey DP (2014) Erratum to "Diversity of snakes in Sarlahi District, Nepal (Vol. 11, No. 2, Page: 201-207, 2013)". Our Nature 12(1): 60-61.

12. Chhettri K, Chhetry DT (2013) Diversity of snakes in Sarlahi District, Nepal. Our Nature 11(2): 201-207.

13. Pandey DP (2015) Venomous snakes of medical relevance in Nepal: study on species, epidemiology of snake bite and assessment of risk factors of envenoming and death. Frankfurt: Goethe University, pp: 231.

14. Bawaskar HS, Bawaskar PH (2002) Profile of snakebite envenoming in western Maharashtra, India. Trans R Soc Trop Med Hyg 96(1): 79-84.

15. Devkota UN, Steinmann JP, Kathayat JB (2001). Epidemiology of snakebite; a study from Choharwa Army Camp, Siraha, Nepal. J Nepal Med Assoc 40: 5762.

16. Sharma SK, Khanal B, Pokhrel P, Khan A, Koirala S (2003) Snakebite-reappraisal of the situation in eastern Nepal. Toxicon 41(3): 285-289.

17. Chippaux JP (1998) Snakebites: appraisal of the global situation. Bull World Health Organ 76(5): 515524.

18. Westly E (2013) One million deaths. Nature 504(7478): 22-23.

19. Heap BJ, Cowan GO (1991) The epidemiology of snakebite presenting to British military hospital Dharan during 1989. J R Army Med Corps 137(3): 123-125.

20. Pandey DP (2006) Epidemiology of snake bites based on hospital survey in Chitwan and Nawalparasi Districts, Nepal. J Nepal Health Res Counc 4(2): 51-57.

21. Pandey DP, Thapa CL, Hamal PK (2010) Impact of first aid training in management of snakebite victims in Madi Valley. J Nepal Health Res Counc 8(1): 5-9.

22. Paudel KM, Sharma S (2012) Study of clinicoepidemiological profile and outcome of poisonous snakebites in children. J Nepal Paediatr Soc 32(1): 4752.
23. Suchithra N, Pappachan J, Sujathan P (2008) Snakebite envenoming in Kerala, South India: clinical profile and factors involved in adverse outcomes. Emerg Med J 25(4): 200-204.

24. Harris JB, Faiz MA, Rahman MR, Jalil MMA, Ahsan MF, et al. (2010) Snakebite in Chittagong Division, Bangladesh: a study of bitten patients who developed no signs of systemic envenoming. Trans $\mathrm{R}$ Soc Trop Med Hyg 104(5): 320-327.

25. Miah MT, Hoque AA, Tarafder BK, Patwary MKH, Khan RR, et al. (2009) Epidemiology, clinical profile and outcome of patients of snake bite in Mymensingh Medical College Hospital. J Bangladesh Coll Phys Surg 27(2): 70-75.

26. Sharma SK, Koirala S, Dahal G, Sah C (2004) Clinicoepidemiological features of snakebite: a study from eastern Nepal. Trop Doct 34(1): 20-22.

27. Sharma N, Chauhan S, Faruqi S, Bhat P, Varma S (2005) Snake envenomation in a north Indian hospital. Emerg Med J 22(2): 118-120.

28. Kumar MR, Veeraprasad M, Babu PR, Kumar SS, Subrahmanyam B, et al. (2014) A retrospective review of snake bite victims admitted in a tertiary level teaching institute. Ann Afr Med 13(2): 76-80.

29. Faiz MA, Rahman MR, Hossain A, Younus EB, Das JC, et al. (1995) A hospital based study of snake bite in Chittagong Medical College. J Bangladesh Coll Phys Surg 13: 3-8.

30. Chakraborty P, Nath JD, Faiz MA, Das A, Chowdhury AQ (2014) Clinical study of snakebite cases admitted in Dhaka Medical College Hospital. Chattagram MaaO-Shishu Hospital Med Coll J 13(1): 7-12.

31. Namal Rathnayaka RMMK, Ranathunga PEAN, Kularatne SAM (2017) Epidemiology and clinical features of Green Pit Viper (Trimeresurus trigonocephalus) envenoming in Sri Lanka. Toxicon 137: 99-105.

32. Mahmood K, Naqvi IH, Talib A, Salkeen S, Abbasi B, et al. (2010) Clinical course and outcome of snake envenomation at a hospital in Karachi. Singapore Med J 51(4): 300-305.

33. Brunda G, Sashidhar RB (2007) Epidemiological profile of snake-bite cases from Andhra Pradesh using immunoanalytical approach. Indian J Med Res 125(5): 661-668. 
34. Hossain J, Biswas A, Rahman F, Mashreky SR, Dalal K, et al. (2016) Snakebite epidemiology in Bangladesh: A national community based health and injury survey. Health 8: 479-486.

35. Ariaratnam CA, Sheriff MHR, Theakston RDG, Warrell DA (2008) Distinctive epidemiologic and clinical features of Common Krait (Bungarus caeruleus) bites in Sri Lanka. Am J Trop Med Hyg 79(3): 458-462.
36. Kularatne AM, Silva A, Maduwage K, Ratnayake I, Walathara C, et al. (2014) Victims' response to snakebite and socio-epidemiological factors of 1018 snakebites in a tertiary care hospital in Sri Lanka. Wilderness Environ Med 25(1): 35-40.

37. World Health Organization (2016) Guidelines for the management of snakebites. 2nd (Edn.), New Delhi: World Health Organization, Regional Office for SouthEast Asia. 